\title{
ATRIBUTOS QUÍMICOS DE SOLO E RESPOSTA DO TRIGO E DA SOJA AO GESSO EM SISTEMA SEMEADURA $\operatorname{DIRETA}^{(1)}$
}

\author{
Leandro Rampim( ${ }^{(2)}$, Maria do Carmo Lana ${ }^{(3)}$, Jucenei Fernando \\ Frandoloso $^{(4)} \&$ Silvano Fontaniva ${ }^{(5)}$
}

\begin{abstract}
RESUMO
A aplicação de gesso para tornar o $\mathrm{Al}$ indisponível, assim como para suprir nutrientes do solo para as plantas, pode proporcionar condições para a obtenção de elevada produtividade das culturas. Este trabalho teve como objetivo avaliar o efeito do gesso $\left(0,1.000,2.000,3.000,4.000\right.$ e $\left.5.000 \mathrm{~kg} \mathrm{ha}^{-1}\right)$ nas características químicas de duas áreas com Latossolo Vermelho eutroférrico de textura argilosa, com ou sem Al trocável, e na nutrição mineral e produtividade das culturas de trigo e soja em sistema semeadura direta. As doses de gesso foram aplicadas em superfície seis meses após a calagem. Aos seis e 12 meses após a aplicação do gesso, foram coletadas amostras de solo nas profundidades de $0-0,10 ; 0,10-0,20$ e $0,20-0,40 \mathrm{~m}$. O uso de até $5.000 \mathrm{~kg} \mathrm{ha}^{-1}$ de gesso resultou em aumento dos teores de

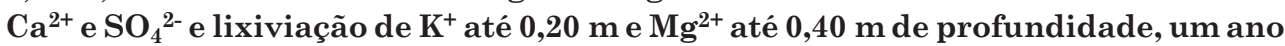
após a aplicação, sendo a dose de $3.000 \mathrm{~kg} \mathrm{ha}^{-1}$ a que proporcionou maior redução do Al trocável. A aplicação de gesso implicou aumento dos teores foliares de Ca e Mg na cultura da soja, redução dos teores de Ca e Mg na cultura do trigo e aumento no teor de $\mathrm{S}$ em ambas as culturas, enquanto o teor de $\mathrm{K}$ aumentou até a dose de $3.170 \mathrm{~kg} \mathrm{ha}^{-1}$ de gesso na cultura da soja. A utilização do gesso eleva a produtividade do trigo, cultivar CD 104, em solo com presença de Al trocável, mas não influencia a produtividade da soja em ambas os solos, com ou sem Al.
\end{abstract}

Termos de indexação: acidez subsuperficial, balanço nutricional, calcário, lixiviação, cátions.

\footnotetext{
(1) Parte da Dissertação de Mestrado do primeiro autor apresentada à Universidade Estadual do Oeste do Paraná, Campus Marechal Cândido Rondon - UNIOESTE. Recebido para publicação em 17 de agosto de 2010 e aprovado em 11 de agosto de 2011.

${ }^{(2)}$ Doutorando em Agronomia - Produção Vegetal, Universidade Estadual do Oeste do Paraná - UNIOESTE. Campus Marechal Candido Rondon (PR). E-mail: rampimleandro@yahoo.com.br

(3) Professora Associada, UNIOESTE. E-mail: maria.lana@unioeste.br

(4) Doutorando em Agronomia - Produção Vegetal, UNIOESTE. E-mail: neiff@bol.com.br

(5) Engenheiro-agrônomo da Agroindustrial Tractur S.A.C.I, Raúl Arsenio Oviedo, Paraguay. E-mail: silvano_fontaniva@yahoo.com.br
} 


\title{
SUMMARY: CHEMICAL ATTRIBUTES OF A SOIL AND RESPONSE OF WHEAT AND SOYBEAN TO GYPSUM IN NO-TILLAGE SYSTEM
}

\begin{abstract}
The application of gypsum can make Al unavailable to plants and provide soil nutrients, improving conditions for high crop yields. This study evaluated the chemical characteristics of Red Latosol, with or without exchangeable Al as influenced by gypsum rates (0, 1000, 2000, 3000,4000 , and $5000 \mathrm{~kg} \mathrm{ha} \mathrm{s}^{-1}$ ) applied to the soil surface, and the effect of gypsum on mineral nutrition and wheat and soybean yields under no-tillage. Gypsum was applied to the surface six months after liming. Six and twelve months after gypsum application, soil samples were collected from the layers 0-0.10, 0.10-0.20 and 0.20-0.40 m. The use of up to $5000 \mathrm{~kg} \mathrm{ha}^{-1}$ gypsum resulted in increased levels of $\mathrm{Ca}^{2+}$ and $\mathrm{SO}_{4}{ }^{2-}$ and leaching of $\mathrm{K}^{+}$to a depth of $0.20 \mathrm{~m}$ and $\mathrm{Mg}^{2+}$ down to $0.40 \mathrm{~m}$, one year after gypsum application. The rate of $3000 \mathrm{~kg} \mathrm{ha}^{-1}$ resulted in greatest $\mathrm{Al}^{3+}$ level reduction. The application of gypsum induced increased Ca and $\mathrm{Mg}$ contents for soybean and reduced Ca and $M g$ content in wheat and increased contents of $S$ in both crops, while K contents increased in soybean up to the $3170 \mathrm{~kg} \mathrm{ha}^{-1}$ gypsum rate. Gypsum increased wheat yields (cultivar CD 104), in soil with presence of Al, but did not influence soybean yield in either soil, with and without Al.
\end{abstract}

Index terms: subsurface acidity, nutritional balance, lime, leaching, cations.

\section{INTRODUÇÃO}

Grande parte dos solos do Brasil apresenta problemas de acidez subsuperficial, uma vez que a incorporação do calcário nem sempre é possível nas lavouras comerciais. Assim, camadas mais profundas do solo, abaixo de $0,20 \mathrm{~m}$, podem continuar com excesso de Al, mesmo quando tenha sido efetuada uma calagem considerada adequada (Caires et al., 2006).

O Al trocável no solo prejudica o crescimento radicular das espécies vegetais sensíveis, reduzindo a exploração do solo. O gesso pode auxiliar na neutralização desse elemento e reduzir sua interferência no crescimento das raízes no subsolo, possibilitando maior produtividade de grãos (Soratto \& Crusciol, 2008a).

O efeito negativo da acidez do solo e da toxidez por $\mathrm{Al}$ na produção agrícola não tem sido observado em sistema plantio direto (SPD); nesse caso, a ausência de resposta das culturas à calagem tem sido comum (Caires et al., 1998, 1999, 2006; Alleoni et al., 2003, 2005). A redução da toxidez do Al encontrada no SPD pode estar associada à sua complexação com ácidos orgânicos, formando complexos com o C orgânico dissolvido, conforme relatado por Zambrosi et al. (2007).

A aplicação de calcário antes de gesso proporciona condições ideais para que o primeiro possa reagir na solução do solo e aumentar o pH, e em seguida o gesso

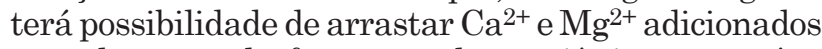
na calagem pela formação de par iônico com o íon sulfato do gesso (Market et al., 1987).

Uma vez na solução do solo, o íon $\mathrm{Ca}^{2+}$ pode reagir no complexo de troca do solo, deslocando $\mathrm{Al}^{3+}, \mathrm{K}^{+} \mathrm{e}$
$\mathrm{Mg}^{2+}$ para a solução do solo, os quais podem, por sua vez, reagir com o $\mathrm{SO}_{4}{ }^{2-}$, formando $\mathrm{AlSO}_{4}{ }^{+}$(que é menos tóxico para as plantas) e os pares iônicos neutros $\mathrm{K}_{2} \mathrm{SO}_{4}{ }^{0}$ e $\mathrm{MgSO}_{4}{ }^{0}$, além do $\mathrm{CaSO}_{4}{ }^{0}$, os quais apresentam grande mobilidade no perfil (Pavan et al., 1984; Dias, 1992).

A gessagem pode ser utilizada em solos ácidos para melhorar as características químicas, como fonte de $\mathrm{Ca}^{2+} \mathrm{e} \mathrm{SO}_{4}{ }^{2-}$, redução dos teores de $\mathrm{Al}^{3+}$ e aumento dos teores de $\mathrm{Ca}^{2+}$, principalmente na subsuperfície do solo (Roth et al., 1986). Com isso, segundo Pavan (1986) e Souza (1996), ocorre maior penetração das raízes em profundidade e, consequentemente, melhora a utilização de água e nutrientes e minimiza os efeitos de veranicos.

Além disso, em Latossolo Vermelho-Escuro com deficiência de $\mathrm{Ca}$ e $\mathrm{S}$ e toxidez de $\mathrm{Al}$ na camada subsuperficial, Tanaka \& Mascarenhas (2002) observaram acréscimos significativos nos teores foliares de S e na produtividade da cultura da soja com a aplicação de gesso. Caires et al. (2002) também encontraram resposta à aplicação de gesso com acréscimo no teor foliar de Ca e $\mathrm{S}$ e aumento quadrático na produtividade da cultura de trigo com a dose máxima de $8.200 \mathrm{~kg} \mathrm{ha}^{-1}$ em Latossolo Vermelho distrófico textura argilosa.

Mascarenhas \& Tanaka (1995), avaliando o crescimento de raízes de cultivares de trigo e soja em função da saturação de Al variando entre 15 e 67 \%, observaram que a cultivar de trigo $\mathrm{BH} 1146$ não apresentou alteração no comprimento das raízes à medida que aumentou a saturação por $\mathrm{Al}$, sendo considerada tolerante ao Al. Entretanto, na cultivar Siete Cerros eles verificaram redução do comprimento 
de raízes com o incremento da saturação por $\mathrm{Al}$, designada sensível ao Al tóxico. Contudo, as cultivares de soja testadas não apresentaram alteração no crescimento das raízes com o aumento da saturação por Al.

Segundo Delhaize et al. (1993), pode ocorrer acúmulo de $\mathrm{Al}$ na epiderme e córtex das raízes em genótipos de trigo sensíveis ao $\mathrm{Al}$, enquanto os genótipos tolerantes liberam o $\mathrm{Al}$ para fora das células das raízes. E, conforme esses autores, o acúmulo de $\mathrm{Al}$ no ápice das raízes dos genótipos sensíveis pode ser cinco vezes maior que em genótipos tolerantes.

Silva et al. (1984a), visando avaliar genótipos de soja sensíveis e tolerantes a diferentes níveis de saturação por Al, observaram que ambos emitiram raízes nas camadas com elevada saturação por $\mathrm{Al}$.

As modificações nos atributos químicos do solo verificadas com a utilização de gesso, tanto nas camadas superficiais quanto nas camadas subsuperficiais, ao fornecerem Ca e S melhoraram a nutrição mineral das espécies vegetais, aumentando a produtividade das culturas comerciais (Silva et al., 1984a; Sousa et al., 1996; Caires et al., 2002; Soratto \& Crusciol, 2008a; Soratto et al., 2010). Em solo com Al trocável, essas modificações proporcionaram sua neutralização, resultando em benefícios para cultivares sensíveis ao $\mathrm{Al}$.

Nesse sentido, este trabalho teve por objetivo avaliar a influência do gesso nas características químicas de duas áreas de Latossolo Vermelho eutroférrico de textura argilosa, com ou sem $\mathrm{Al}$ trocável, assim como a sua influência nos teores foliares de $\mathrm{Al}, \mathrm{Ca}, \mathrm{Mg}, \mathrm{K}$ e $\mathrm{S}$ e na produtividade das culturas de trigo e soja sob sistema semeadura direta.

\section{MATERIAL E MÉTODOS}

O experimento foi realizado em duas propriedades do município de Guaíra, PR, caracterizadas como Local 1 (latitude: $24^{\circ} 09^{\prime} 12^{\prime \prime} \mathrm{S}$; longitude: $54^{\circ} 12$ '23” W) e Local 2 (latitude: $24^{\circ} 18^{\prime} 38^{\prime \prime} \mathrm{S}$; e longitude: $54^{\circ} 12$ '12” W). As áreas vinham sendo utilizadas em sistema semeadura direta há 15 anos em sucessão de culturas, utilizando soja no verão e trigo/milho no inverno, em Latossolo Vermelho eutroférrico textura muito argilosa de média fertilidade (Embrapa, 2006), com a presença de $\mathrm{Al}^{3+}$ no Local 1 (c/Al) e de alta fertilidade e ausência de $\mathrm{Al}^{3+}$ no Local 2 (s/Al), cujas caracterizações físicas e químicas anteriores à aplicação dos tratamentos constam no quadro 1.

Nos dois locais, no dia primeiro de outubro de 2005, seis meses antes da instalação do experimento, foi realizada a calagem superficial com a aplicação de $1.650 \mathrm{~kg} \mathrm{ha}^{-1}$ de calcário calcítico com PRNT de 70 \%, seguida de subsolagem profunda, em função da presença de adensamento na camada entre 0,15$0,30 \mathrm{~m}$ no solo e posterior cultivo da soja.

Quadro 1. Resultado das análises química e física do solo da área experimental, a partir da coleta inicial de solo realizada em março de 2006 , nas profundidades de $0-0,10,0,10-0,20$ e 0,20-0,40 m dos dois locais, com ou sem Al trocável, em Latossolo Vermelho eutroférrico de textura argilosa

\begin{tabular}{|c|c|c|c|c|c|c|}
\hline \multirow{2}{*}{ Característica } & \multicolumn{3}{|c|}{ Local $1^{(\mathrm{c} / \mathrm{Al})}$} & \multicolumn{3}{|c|}{ Local $2^{(\mathrm{s} / \mathrm{Al})}$} \\
\hline & $0-0,10 \mathrm{~m}$ & $0,10-0,20 \mathrm{~m}$ & $0,20-0,40 \mathrm{~m}$ & $0-0,10 \mathrm{~m}$ & $0,10-0,20 \mathrm{~m}$ & $0,20-0,40 \mathrm{~m}$ \\
\hline $\mathrm{pH}^{(1)}$ & 4,80 & 4,10 & 4,10 & 5,80 & 5,40 & 4,80 \\
\hline $\mathrm{Al}^{3+(2)}\left(\mathrm{cmol}_{\mathrm{c}} \mathrm{dm}^{-3}\right)$ & 0,20 & 0,35 & 0,45 & 0,00 & 0,00 & 0,00 \\
\hline $\mathrm{H}+\mathrm{Al}^{(3)}\left(\mathrm{cmol}_{c} \mathrm{dm}^{-3}\right)$ & 4,61 & 4,28 & 4,96 & 3,40 & 3,60 & 3,90 \\
\hline $\mathrm{Ca}^{2+(2)}\left(\mathrm{cmol}_{\mathrm{c}} \mathrm{dm}^{-3}\right)$ & 4,77 & 4,04 & 3,77 & 6,20 & 6,03 & 5,89 \\
\hline $\mathrm{Mg}^{2+(2)}\left(\mathrm{cmol}_{\mathrm{c}} \mathrm{dm}^{-3}\right)$ & 1,98 & 1,85 & 1,60 & 1,64 & 1,50 & 1,40 \\
\hline $\mathrm{K}^{+(4)}\left(\mathrm{cmol}_{\mathrm{c}} \mathrm{dm}^{-3}\right)$ & 0,59 & 0,35 & 0,26 & 0,40 & 0,35 & 0,28 \\
\hline $\mathrm{SB}\left(\mathrm{cmol}_{\mathrm{c}} \mathrm{dm}^{-3}\right)$ & 7,34 & 6,24 & 5,63 & 8,24 & 7,88 & 7,57 \\
\hline CTC pH 7,0 $\left(\mathrm{cmol}_{\mathrm{c}} \mathrm{dm}^{-3}\right)$ & 11,95 & 10,52 & 10,59 & 11,64 & 11,48 & 11,47 \\
\hline $\mathrm{V}(\%)$ & 61,42 & 59,32 & 53,16 & 70,79 & 68,64 & 66,00 \\
\hline m (\%) & 2,65 & 5,31 & 7,40 & 0,00 & 0,00 & 0,00 \\
\hline $\mathrm{MO}\left(\mathrm{g} \mathrm{kg}^{-1}\right)$ & 20,00 & 15,00 & 11,00 & 26,00 & 22,00 & 19,00 \\
\hline $\left.\mathrm{P}^{(4)}(\mathrm{mg} \mathrm{dm})^{-3}\right)$ & 12,32 & 7,19 & 3,11 & 15,00 & 12,00 & 8,00 \\
\hline $\mathrm{S}^{(5)}\left(\mathrm{mg} \mathrm{dm}^{-3}\right)$ & 11,43 & 18,50 & 21,49 & 9,27 & 9,50 & 12,15 \\
\hline $\mathrm{Cu}^{(4)}\left(\mathrm{mg} \mathrm{dm}^{-3}\right)$ & 3,30 & 4,10 & 4,60 & 4,00 & 4,30 & 4,40 \\
\hline $\operatorname{Mn}^{(4)}\left(\mathrm{mg} \mathrm{dm}^{-3}\right)$ & 75,00 & 69,00 & 46,00 & 77,00 & 60,00 & 57,00 \\
\hline $\mathrm{Zn}^{(4)}\left(\mathrm{mg} \mathrm{dm}^{-3}\right)$ & 2,70 & 2,30 & 1,40 & 3,30 & 2,90 & 2,50 \\
\hline $\mathrm{Fe}^{(4)}\left(\mathrm{mg} \mathrm{dm}^{-3}\right)$ & 19,10 & 25,40 & 24,50 & 21,00 & 26,00 & 29,00 \\
\hline Areia ${ }^{(6)}\left(\mathrm{g} \mathrm{kg}^{-1}\right)$ & 66 & 74 & 55 & 63 & 64 & 64 \\
\hline Silte $^{(6)}\left(\mathrm{g} \mathrm{kg}^{-1}\right)$ & 204 & 129 & 145 & 190 & 132 & 133 \\
\hline Argila $^{(6)}\left(\mathrm{g} \mathrm{kg}^{-1}\right)$ & 730 & 797 & 800 & 747 & 804 & 803 \\
\hline
\end{tabular}

${ }^{(1)} \mathrm{pH}$ em $\mathrm{CaCl}_{2}$, relação 1:2,5. ${ }^{(2)}$ Extrator $\mathrm{KCl} 1 \mathrm{~mol} \mathrm{~L}^{-1}$. ${ }^{(3)}$ Extrator acetato de cálcio $0,5 \mathrm{~mol} \mathrm{~L}{ }^{-1} \mathrm{pH} 7,0 .{ }^{(4)}$ Extrator $\mathrm{Mehlich-1.}$

(5) Extrator $\mathrm{Ca}\left(\mathrm{H}_{2} \mathrm{PO}_{4}\right)_{2} 500 \mathrm{mg} \mathrm{L}^{-1}$ de $\mathrm{P}$ em HOAc $2 \mathrm{~mol} \mathrm{~L}^{-1}$ (Embrapa, 1999). ${ }^{(6)}$ Método do densímetro (Embrapa, 1997). 
O experimento foi realizado em delineamento de blocos casualizados com seis repetições. Foram avaliadas seis doses de gesso agrícola (17\% de Ca, $15 \%$ de $\mathrm{SO}_{4}$ ), compreendendo a ausência de gessagem (dose 0) e as doses de 1.000, 2.000, 3.000, 4.000 e $5.000 \mathrm{~kg} \mathrm{ha}^{-1}$ de gesso, num total de 36 parcelas experimentais por local de cultivo (solos com ou sem $\mathrm{Al}^{3+}$ ). A instalação do experimento foi realizada sobre a palhada oriunda da cultura da soja. A aplicação do gesso em superfície em dose única foi realizada em abril de 2006, portanto seis meses após a aplicação de calcário. As parcelas avaliadas tinham área total de $12,00 \mathrm{~m}^{2}$ e área útil de $1,92 \mathrm{~m}^{2}$ para a cultura do trigo e 5,40 $\mathrm{m}^{2}$ para a cultura da soja. A precipitação pluvial mensal no período de abril de 2006 e março de 2007 , durante a realização do experimento, foi de $1.535 \mathrm{~mm}$ no Local 1 (c/Al) e 1.528 mm no Local 2 (s/Al) (Figura 1).

Durante o período de realização do experimento, efetuou-se, inicialmente, o cultivo de trigo, implantado em oito de maio de 2006, no espaçamento de 0,17 m, densidade de 68 sementes por metro linear e estande final de 64,6 plantas. O cultivo da soja foi realizado após a colheita do trigo, implantado em dois de outubro de 2006, no espaçamento de 0,45 m, densidade de 18 sementes por metro linear e estande final de 14,85 plantas. Na semeadura de trigo, utilizou-se a variedade CD 104, por ser a mais empregada na região, classificada como moderadamente sensível à presença de $\mathrm{Al}^{3+}$. Na semeadura da soja foi utilizada a variedade transgênica CD 214RR, mais adequada para a região e caracterizada como tolerante ao $\mathrm{Al}^{3+}$.

As coletas das amostras de solos foram efetuadas em outubro de 2006 e abril de 2007. Após cada cultivo foram retiradas, na entrelinha da cultura em cada parcela, três amostras simples para compor uma amostra composta de solo nas profundidades de 0 0,10, 0,10-0,20 e 0,20-0,40 m, para avaliar os teores de $\mathrm{Ca}^{2+}, \mathrm{Mg}^{2+}, \mathrm{K}^{+}, \mathrm{S}, \mathrm{Al}^{3+}$ e $\mathrm{pH}$ do solo, segundo Embrapa (1999). Nas culturas de trigo e soja foram coletadas amostras de tecido foliar em pleno florescimento, conforme os procedimentos recomendados quanto à época e folhas amostradas por Malavolta et al. (1997), para a determinação dos teores de $\mathrm{Ca}, \mathrm{Mg}, \mathrm{K}$, S e Al (Embrapa, 1999). Nas culturas de soja e trigo foi avaliada a produtividade. No ponto de colheita, foi realizada a coleta da parte aérea das plantas da cultura do trigo em 15 de setembro de 2006 e da soja em 3 de março de 2007, trilhando-as em Trilhadeira Vencedora B-150 para a obtenção dos grãos, os quais foram pesados para determinação da produtividade, com posterior padronização da umidade das amostras para $13 \%$ na cultura do trigo e $14 \%$ na da soja.

O S no solo foi extraído por $\mathrm{Ca}\left(\mathrm{H}_{2} \mathrm{PO}_{4}\right)_{2} 500 \mathrm{mg} \mathrm{L}^{-1}$ de $\mathrm{P}$ em HOAc $2 \mathrm{~mol} \mathrm{~L}^{-1}$ e dosado por turbidimetria em espectrofotometria UV-vis. Enquanto no teor de $\mathrm{S}$ foliar as amostras de tecido vegetal foram digeridas previamente em solução ácida $\left(\mathrm{HNO}_{3}\right.$ e $\left.\mathrm{HClO}_{4}\right)$ e dosadas por turbidimetria (Embrapa, 1999). O teor de Al foliar foi determinado pelo complexo colorido formado entre o $\mathrm{Al}$ e o reagente orgânico eriocromo cianina $\mathrm{R}$ (ECR), que absorve luz em comprimento de onda de $535 \mathrm{~nm}$, sendo esse complexo estável entre 10 e 30 min (Embrapa, 1999).

Inicialmente, submeteram-se os dados à análise de variância de cada local em separado, e avaliaramse os valores dos quadrados médios dos resíduos dos locais em todas as variáveis. E os dados de ambos os locais foram analisados de forma conjunta, em virtude do fato de que a razão entre os quadrados médios dos resíduos dos locais foi inferior a 7 , de acordo com Pimentel Gomes (1987).

$\mathrm{Na}$ análise de variância, avaliou-se o efeito das doses de gesso por ajuste de regressão utilizando o programa SAEG 8.0 (SAEG, 1999). Os modelos que melhor se ajustaram aos dados foram escolhidos com base na significância pelo teste $\mathrm{F}$, considerando-se os níveis de 5 e $1 \%$ e do maior valor do coeficiente de

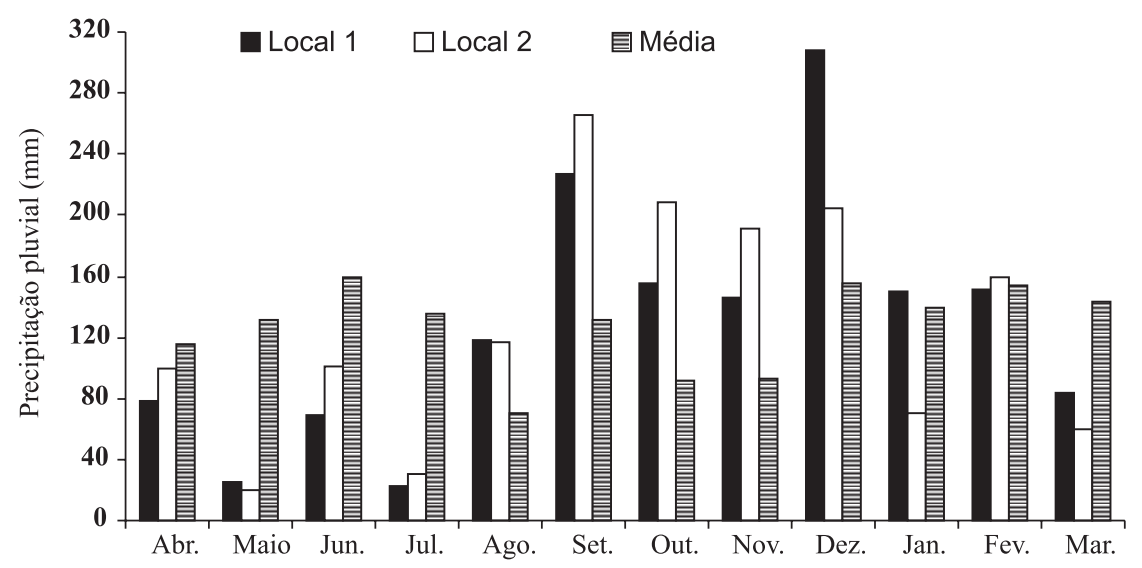

Figura 1. Precipitação pluvial mensal do Local 1 (c/Al) e Local 2 (s/Al), no período da experimentação no campo, entre abril de 2006 e março de 2007, e precipitação média mensal de 1973 a 2009 , medidas na Estação Meteorológica de Palotina, PR. 
determinação. Contudo, a partir da avaliação do teste F para Local (com ou sem Al), na análise de variância foi significativo nas variáveis $\mathrm{Al}^{3+}$, teor de $\mathrm{S}$ na soja e $\mathrm{Ca}, \mathrm{Mg}$ e produtividade em ambas as culturas, fato que direcionou a análise de variância dessas variáveis para cada local.

\section{RESULTADOS E DISCUSSÃO}

\section{Atributos químicos do solo}

A adição de gesso ao solo até a dose de $5.000 \mathrm{~kg} \mathrm{ha}^{-1}$ não influenciou nos valores de $\mathrm{pH}$ do solo nas três profundidades avaliadas, resultados também observados por Pavan et al. (1984), Alcarde (1992), Caires et al. (2003) e Ramos et al. (2006), à exceção dos 12 meses após a aplicação, em que houve efeito significativo na camada de $0,10-0,20 \mathrm{~m}$. O valor máximo de $\mathrm{pH}$ encontrado na camada de $0,10-0,20 \mathrm{~m}$ foi de 4,88, com a aplicação de $2.250 \mathrm{~kg} \mathrm{ha}^{-1}$ de gesso (Figura 2ab). $\mathrm{O}$ aumento do $\mathrm{pH}$ pode ser resultado da lixiviação do gesso na camada de $0,10-0,20 \mathrm{~m}$, na qual pode ter ocorrido sua dissociação, liberando $\mathrm{Ca}^{2+}$ que se liga ao $\mathrm{C}$ orgânico, tornando o $\mathrm{SO}_{4}{ }^{2-}$ disponível na solução do solo para a substituição do $\mathrm{OH}^{-}$, forma química que na solução também interfere no aumento do $\mathrm{pH}$ e na redução da acidez por $\mathrm{Al}^{3+}$ (Soratto \& Crusciol, 2008a), principalmente em solos com predomínio de cargas variáveis como os Latossolos (Pavan, 1986), concordando com os resultados encontrados por Raij et al. (1994) e Caires et al. (2003).

As culturas de trigo e soja podem ter influenciado no valor do $\mathrm{pH}$ do solo, uma vez que, aos seis meses após o cultivo de trigo, o $\mathrm{pH}$ foi maior quando comparado aos 12 meses após o cultivo da soja (Figura 2ab). A cultura da soja ao fixar $\mathrm{N}_{2}$ deixa de absorver $\mathrm{N}_{-} \mathrm{NO}_{3}{ }^{-}$, acidificando o solo, como discutido por Maschner (1995), tal qual a cultura da soja apresenta rizosfera com $\mathrm{pH}$ mais baixo. No entanto, Haynes (1990) relatou que na cultura de trigo o balanço cátion-ânion no citoplasma proporciona acúmulo e degradação de ácidos orgânicos que são liberados pelas raízes, complexando o $\mathrm{Al}^{3+}$ no solo, além da absorção
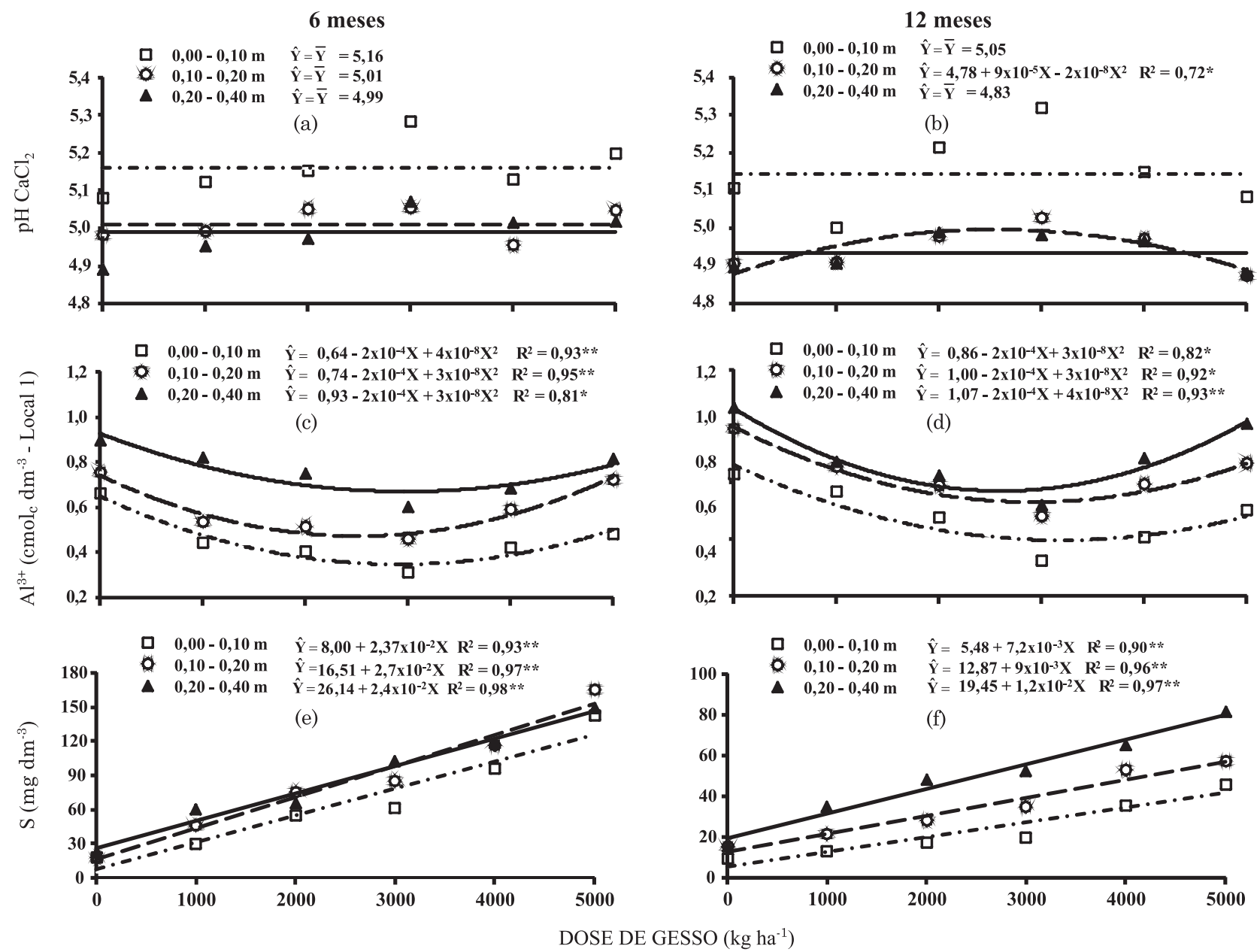

Figura 2. Valor de pH $\mathrm{CaCl}_{2}$ aos seis (a) e 12 meses (b), teor de $\mathrm{Al}^{3+}$ aos seis (c) e 12 meses no Local 1 (c/Al), (d) e de enxofre aos seis (e) e 12 meses (f), no solo nas camadas de 0-0,10, 0,10-0,20 e 0,20-0,40 m de profundidade, após a aplicação de doses de gesso agrícola na média de dois locais. * e ${ }^{* *}$ significativos a 5 e $1 \%$, com base na significância pelo teste $\mathrm{F}$. 
preferencial de ânions que liberam mais $\mathrm{OH}^{-}$na rizosfera, aumentando o $\mathrm{pH}$.

No Local 2 (s/Al) não havia $\mathrm{Al}$ trocável no solo e, com a adição de gesso, tal condição permaneceu em todas as camadas (Figura 2cd). Não obstante, houve redução quadrática no teor de $\mathrm{Al}$ trocável no solo no Local 1 (c/Al) em função das doses de gesso. Isso reforça a ocorrência de trocas iônicas de $\mathrm{Al}^{3+}$ por $\mathrm{Ca}^{2+}$, deslocando Al para a solução, o qual pode ser imobilizado pelo $\mathrm{SO}_{4}{ }^{2-}$ (Pavan et al., 1984) e carbono orgânico (Zambrosi et al., 2007). A maior redução no teor de $\mathrm{Al}^{3+}$ foi obtida com o uso da dose de $3.000 \mathrm{~kg} \mathrm{ha}^{-1}$ nas três camadas avaliadas, tanto aos seis quanto aos 12 meses, condizendo com Souza et al. (1996).

Neste trabalho, observou-se a redução de $\mathrm{Al}$ trocável para o Local 1 (c/Al) (Figura 2cd) e incremento de Ca (Figura 3ab), os quais interferem na saturação por Al, reduzindo-a. Tais resultados são comprovados por Pavan et al. (1984), visto que solos com alta saturação por $\mathrm{Al}^{3+}$ e baixo teor de $\mathrm{Ca}^{2+}$, como o Local 1
(c/Al), os efeitos do gesso são mais pronunciados (Pavan, 1986). Entretanto, Caires et al. (2007) encontraram redução da saturação por $\mathrm{Al}^{3+}$ ocasionada basicamente pelo aumento de $\mathrm{Ca}^{2+}$, em vista de o teor de $\mathrm{Al}^{3+}$ não ter sido influenciado pela aplicação de gesso.

De forma geral, neste trabalho o uso de gesso proporcionou aumento de $\mathrm{Ca}^{2+}$ em todas as camadas, redução de $\mathrm{Mg}^{2+}$ nas camadas superficiais e acréscimo de $\mathrm{S}$ em todas as camadas, arrastando cátions como $\mathrm{K}^{+}, \mathrm{Mg}^{2+}$ e $\mathrm{Ca}^{2+}$ e melhorando as condições subsuperficiais (Figura 3). Resultados semelhantes também foram encontrados por Rosolem et al. (1984), Alcarde (1992), Wadt (2000), Caires et al. (2003) e Silva et al. (2006) em experimentos com gesso. A mobilidade de cátions observada no trabalho pode ter ocorrido devido à formação de pares iônicos neutros com o $\mathrm{SO}_{4}{ }^{2-}$, pela ação do Ca dissociado do gesso (Dias, 1992), como também pode ter sido auxiliado pela mobilidade de cátions ligados aos ácidos orgânicos dos restos culturais (Franchini et al., 2001, 2003).

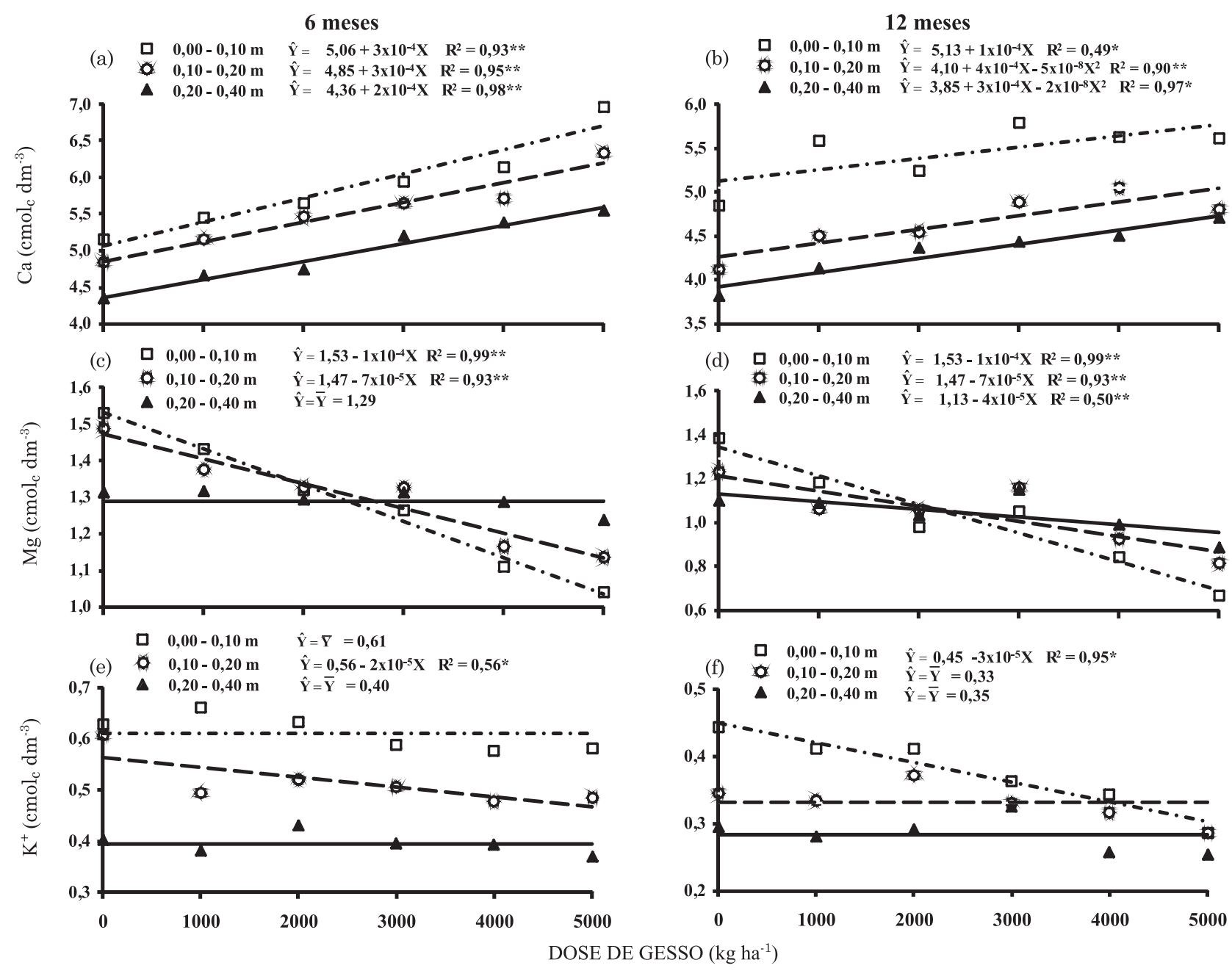

Figura 3. Teor de cálcio aos seis (a) e 12 meses (b), magnésio aos seis (c) e 12 meses (d) e potássio aos seis (e) e 12 meses (f), no solo nas camadas de 0-0,10, 0,10-0,20 e 0,20-0,40 m de profundidade, após a aplicação de doses de gesso agrícola na média de dois locais. * e ${ }^{* *}$ significativos a 5 e $1 \%$, com base na significância pelo teste $F$. 


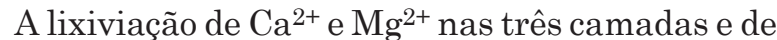
$\mathrm{K}^{+}$na profundidade de 0,10-0,20 m também foi constatada por Dias (1992), que verificou que o uso de gesso em solos sem problemas de acidez subsuperficial, como é o caso do Local 2 (s/Al), pode aumentar a lixiviação de bases pela formação de pares iônicos $\mathrm{CaSO}_{4}{ }^{0}, \mathrm{MgSO}_{4}{ }^{0}$ e $\mathrm{K}_{2} \mathrm{SO}_{4}{ }^{0}$ e reduzir o seu nível de fertilidade, como observado por Pavan (1986). A forma de $\mathrm{MgSO}_{4}{ }^{0}$ é prioritária sobre outros pares iônicos (Zambrosi et al., 2007), evidenciando o carregamento de $\mathrm{Mg}^{2+}$ para as camadas subsuperficiais (Figura $3 \mathrm{~cd}$ ).

A redução no teor de $\mathrm{Mg}^{2+}$ observada nas camadas de 0-0,10 e 0,10-0,20 $\mathrm{m}$ de profundidade com a adição de gesso (Figura 3cd) pode proporcionar eventuais deficiências desse elemento, segundo trabalho de Shainberg et al. (1989), desde que atinja a concentração mínima exigida para cada cultura. Tal efeito pode ser verificado na cultura do trigo, em que houve redução nos teores foliares de $\mathrm{Mg}^{2+}$ com o aumento das doses de gesso (Figura 4b). Zambrosi et al. (2007) também verificaram lixiviação de $\mathrm{Mg}^{2+} \mathrm{e}$ reportaram que tal lixiviação foi devida à substituição do $\mathrm{Mg}^{2+}$ pelo $\mathrm{Ca}^{2+}$ nas cargas negativas do solo e que a presença do sulfato favorece a lixiviação desse cátion, na forma de $\mathrm{MgSO}_{4}{ }^{0}$. Todo o $\mathrm{Mg}^{2+}$ lixiviado das camadas $0-0,10$ e $0,10-0,20 \mathrm{~m}$ não ficou retido na camada de 0,20-0,40 m, ocorrendo lixiviação além dessa camada (Figura 3cd). A menor CTC e o menor teor de matéria orgânica na camada de 0,20-0,40 m (Quadro 1) possivelmente influenciaram na menor retenção de cátions nessa camada.

Com relação ao $\mathrm{K}^{+}$, foi verificada lixiviação apenas nas camadas de $0-0,10 \mathrm{~m}$ aos 12 meses e de 0,10 $0,20 \mathrm{~m}$ aos seis meses (Figura 3ef). No entanto, não houve acúmulo do $\mathrm{K}^{+}$lixiviado na camada de 0,20 $0,40 \mathrm{~m}$, o qual pode ter sido arrastado para profundidade além de 0,40 m. Não obstante, Wadt \& Wadt (1999), em Latossolo Vermelho-Amarelo textura argilosa, também encontraram lixiviação de $\mathrm{K}^{+}$nas camadas superficiais com a utilização de gesso.

Foi possível verificar aos seis meses após a aplicação de gesso a magnitude de solubilização e interferência nas características químicas do solo (Figuras 2 e 3). Tal solubilização e alteração nas características químicas do solo também foram constatadas por Quaggio et al. (1993), em que 18 meses após a aplicação do gesso praticamente todo o $\mathrm{Ca}^{2+} \mathrm{e}$ $\mathrm{SO}_{4}{ }^{2-}$ adicionados foram lixiviados para profundidades maiores que $0,40-0,60 \mathrm{~m}$.

$\mathrm{O}$ gesso aplicado proporcionou incremento no teor de $\mathrm{S}$ nas três profundidades (Figura 2ef), sendo aos seis meses em maior magnitude, mostrando a alta solubilidade do gesso e que a calagem antecipada proporcionou maior mobilidade do $\mathrm{SO}_{4}{ }^{2-}$ no perfil do solo. Nogueira \& Melo (2003) observaram que o máximo teor de $\mathrm{SO}_{4}{ }^{2-}$ disponível no solo ocorreu aos 21 dias nas camadas de $0,0-0,20$ e 0,20-0,40 m após a aplicação do gesso e a incorporação com gradagem leve. A solubilização rápida do gesso também foi identificada por Zambrosi et al. (2007), os quais verificaram maior concentração de $\mathrm{SO}_{4}{ }^{2-}$ na solução do solo carregado pela água da precipitação pluvial, concordando com este trabalho, em que a concentração de $\mathrm{SO}_{4}{ }^{2-}$ observada aos seis meses nas camadas do solo foi maior que aos 12 meses após a aplicação de gesso.

$\mathrm{O}$ gesso aplicado em sistema semeadura direta no Local 1 (c/Al) e no Local 2 (s/Al) mobiliza, dessa forma, nas camadas mais profundas cátions e enxofre, fato que melhora o enraizamento das plantas, favorece a ciclagem de nutrientes no solo e amplia a área de absorção de água, principalmente em situações de estresse hídrico, como observado por Roth et al. (1986), Borges (1997) e Soratto \& Crusciol (2008b).

Para que não ocorra redução acentuada nos teores de $\mathrm{Mg}^{2+} \mathrm{e} \mathrm{K}^{+}$em profundidade (Figura 3cf), pode-se sugerir a dose de $3.000 \mathrm{~kg} \mathrm{ha}^{-1}$ de gesso em área com sistema semeadura direta em solo muito argiloso. Essa dose proporcionou maior redução no teor de $\mathrm{Al}^{3+}$ trocável (Figura 2cd), condizendo com os resultados encontrados por Sousa et al. (1996) em SPD; além disso, a dose de $3.000 \mathrm{~kg} \mathrm{ha}^{-1}$ proporcionou o máximo de incremento no teor de $\mathrm{S}$ foliar para as culturas do trigo e da soja (Figura 4d), assim como o máximo de incremento no teor de $\mathrm{K}$ para a cultura da soja (Figura 4c) e acréscimo na produtividade da cultura do trigo (Figuras 4f).

\section{Teor foliar}

A aplicação de doses crescentes de gesso na cultura do trigo não interferiu significativamente no teor de Al no tecido foliar, mesmo a cultivar de trigo CD 104 sendo moderadamente sensível ao Al (Figura 4e). Segundo Haynes (1990), a cultura do trigo pode ter mecanismos de tolerância ao $\mathrm{Al}$, como complexação de Al no citoplasma por ácidos orgânicos, armazenamento de $\mathrm{Al}$ no vacúolo e exsudação de quelatos ligantes, que ao ocorrerem nas raízes evitam que o $\mathrm{Al}$ atinja a parte aérea da planta. Assim, a cultivar CD 104, com a atuação de um entre esses mecanismos de tolerância ao $\mathrm{Al}$ nas raízes, foi suficiente para evitar o direcionamento de $\mathrm{Al}$ às folhas.

$\mathrm{Na}$ cultura da soja cultivar CD 214RR ocorreu, entretanto, aumento do teor de $\mathrm{Al}$ no tecido foliar em função das doses crescentes de gesso, visto que a aplicação deste proporcionou melhoria nas propriedades químicas das camadas subsuperficiais, fato que pode ter proporcionado aumento de raízes nessas camadas, onde a concentração do $\mathrm{Al}$ é maior, absorvendo-o mais intensamente, e o $\mathrm{Al}^{3+}$ é um cátion e compete com $\mathrm{Ca}^{2+}, \mathrm{Mg}^{2+}$ e $\mathrm{K}^{+}$pelos sítios de absorção nas plantas. E mais, a tolerância ao $\mathrm{Al}^{3+}$ pode ocorrer por diversos mecanismos (Haynes, 1990), que no caso da cultura da soja, cultivar CD 214RR, pode estar relacionada ao armazenamento de $\mathrm{Al}$ no vacúolo, fato que evidência o aumento do teor foliar de $\mathrm{Al}$ nessa cultivar. 

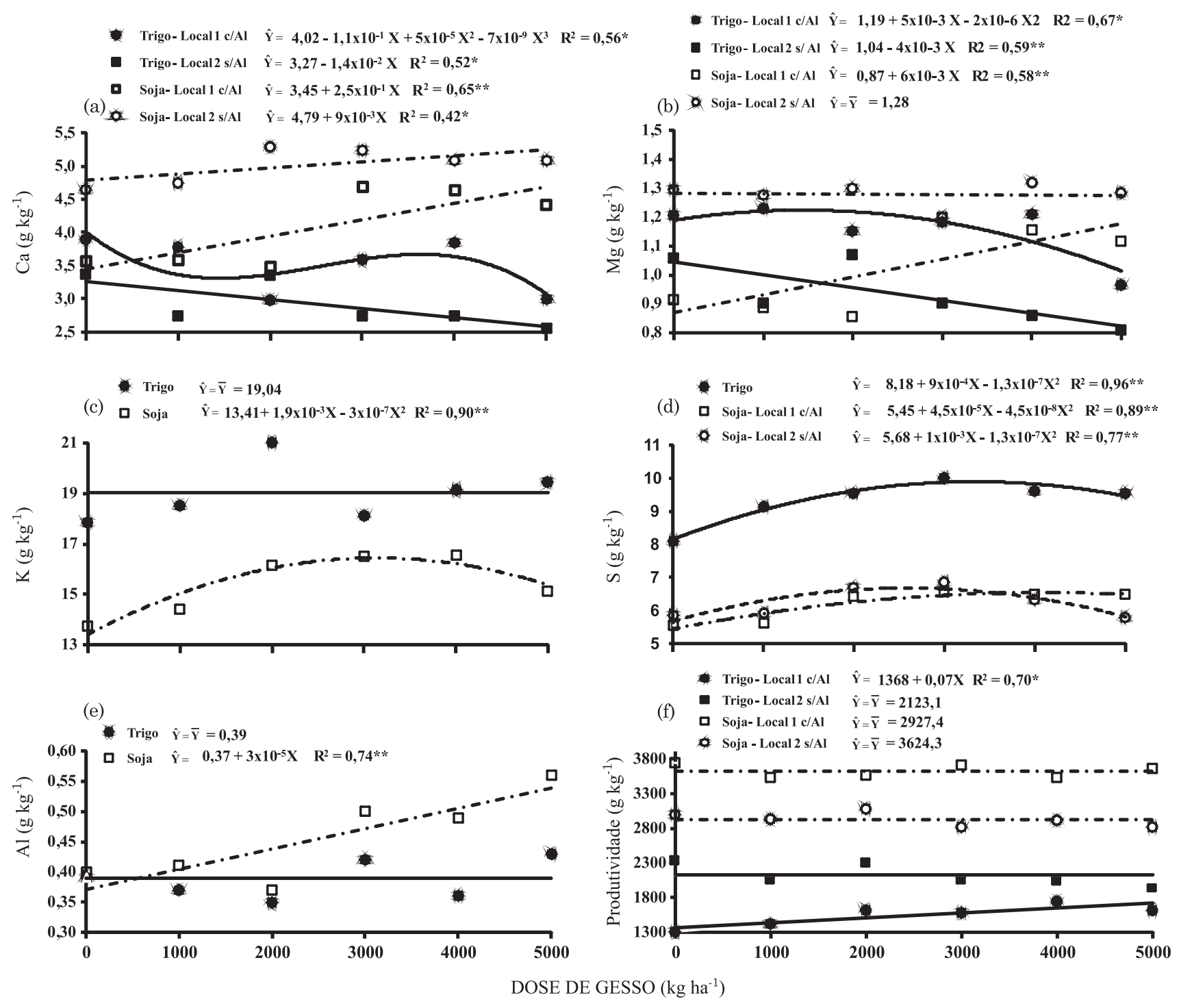

Figura 4. Teores foliares de cálcio (a), magnésio (b), potássio (c), enxofre (d), alumínio (e) e produtividade (f) das culturas de trigo e soja em função das doses de gesso agrícola. * e ** significativos a 5 e $1 \%$, com base na significância pelo teste $\mathrm{F}$.

Na cultura da soja houve efeito linear crescente na adição das doses de gesso nos teores de Ca e Mg no tecido foliar (Figura 4ab). No Local 2 (s/Al) houve maiores teores de Ca e Mg no tecido foliar da cultura da soja, correlacionando com concentrações de $\mathrm{Ca}^{2+} \mathrm{e}$ $\mathrm{Mg}^{2+}$ mais elevadas no solo (Quadro 1). Não obstante, o incremento do teor de Ca encontrado no tecido foliar da soja (Figura 4a) com o uso do gesso também foi verificado por Quaggio et al. (1993).

A redução na absorção de $\mathrm{Mg}$ no tecido foliar da cultura do trigo pode ser devida à alta solubilidade do gesso, pois propicia lixiviação de $\mathrm{Mg}^{2+}$ das camadas superficiais e principalmente aumento da relação $\mathrm{Ca}^{2+} /$ $\mathrm{Mg}^{2+}$ com o incremento de $\mathrm{Ca}^{2+}$, fato que resulta em aumento na competição pelos sítios de absorção. Resultados semelhantes foram observados por Soratto \& Crusciol (2008b) em experimento envolvendo gradagem e subsolagem dois anos antes do cultivo da aveia-preta e por Soratto \& Crusciol (2007) com feijão em sistema semeadura direta, quando essas culturas foram submetidas à aplicação de doses de calcário dolomítico em detrimento da aplicação de gesso.

Caires et al. (2003) constataram, todavia, que o gesso proporciona redução de $\mathrm{Mg}^{2+}$ nas camadas superficiais, com acúmulo em camadas subsuperficiais em Latossolo Vermelho distrófico com $0,2 \mathrm{cmol}_{\mathrm{c}} \mathrm{dm}^{-3}$ de $\mathrm{Mg}^{2+}$ e redução do teor de $\mathrm{Mg}$ no tecido foliar da soja, visto que a lixiviação de $\mathrm{Mg}$ prejudicou a absorção desse nutriente pelas plantas, como ocorreu na cultura do trigo (Figuras 3cd e 4b). A deficiência de $\mathrm{Mg}$ encontrada por Caíres et al. (2003) com a aplicação de 3.000 a $9.000 \mathrm{~kg} \mathrm{ha}^{-1}$ de gesso ocorreu em decorrência do baixo teor de $\mathrm{Mg}^{2+}$ no solo. Contudo, neste estudo esse problema foi minimizado devido ao alto teor de 
$\mathrm{Mg}^{2+}$ no solo, entre 1,64 e $1,98 \mathrm{cmol}_{\mathrm{c}} \mathrm{dm}^{-3}$ no solo com e sem Al.

A aplicação de gesso interferiu negativamente nos teores de $\mathrm{Ca}$ e $\mathrm{Mg}$ na cultura do trigo, enquanto a cultura da soja demonstrou ganhos significativos desses elementos no tecido foliar (Figura 4ab). Dessa forma, é necessário avaliar as características químicas do solo para a recomendação de gesso antes da cultura do trigo, pois o gesso prejudicou a absorção de Ca e Mg. Uma opção é a aplicação de gesso antes da instalação da cultura da soja, visto que esse insumo incrementou os teores dos nutrientes no tecido foliar dessa cultura.

$\mathrm{O}$ incremento do teor de $\mathrm{K}$ no tecido foliar da soja com o uso do gesso, alcançando teor máximo de $16,4 \mathrm{~g} \mathrm{~kg}^{-1}$ com a dose de $3.160 \mathrm{~kg} \mathrm{ha}^{-1}$ de gesso, pode estar relacionado ao ponto de equilíbrio na relação entre $\mathrm{Ca}, \mathrm{Mg}$ e K, em que ocorre intensa absorção de $\mathrm{K}$ pela cultura da soja, e a partir dessa dose de gesso inicia-se um aumento no teor de $\mathrm{Ca}^{2+}$ no solo, o qual prejudicaria a absorção de K. Quanto ao teor de K do trigo não houve efeito significativo, com teor médio de $19 \mathrm{~g} \mathrm{~kg}^{-1}$, valor abaixo do considerado adequado por Malavolta et al. (1997), mesmo com teores adequados de K no solo (Figuras 4c e 3ef). A absorção de K pode ter sido prejudicada pela menor precipitação pluvial durante a cultura do trigo (Figura 1).

Nessa cultura, pelo fato de ter sido instalada logo após a aplicação do gesso, com o aumento das doses houve redução nos teores de $\mathrm{Ca}$, enquanto o $\mathrm{K}$ permaneceu inalterado. Todavia, como o teor de $\mathrm{Ca}^{2+}$ do solo no Local 2(s/Al) já estava alto (Quadro 1), o uso do gesso pode ter prejudicado a absorção do $\mathrm{Mg}$ na cultura do trigo, enquanto no Local 1(c/Al), como o teor de Ca estava mais baixo, ocorreu aumento do teor de $\mathrm{Mg}$ até $1.000 \mathrm{~kg} \mathrm{ha}^{-1}$ de gesso e decréscimo a partir dessa dose (Figura 4ab).

Como a cultura do trigo tem menor CTC radicular, há favorecimento da retenção de cátions monovalentes como o $\mathrm{K}^{+}$, enquanto a cultura da soja apresenta maior CTC radicular e ocorre maior retenção de cátions

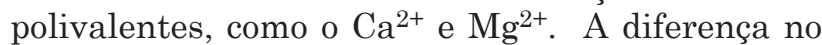
comportamento da absorção de $\mathrm{Ca}, \mathrm{Mg}$ e $\mathrm{K}$ nas culturas do trigo e da soja também foi observada entre espécies dicotiledôneas com maior CTC radicular e monocotiledôneas com menor CTC radicular, como relatado por Marschner (1995).

O aumento nos teores foliares de Ca e S na cultura da soja (Figura 4ad) também foi verificado em trabalho realizado por Silva et al. (1997) na cultura do algodoeiro, o que resultou também em ganhos de produtividade com a aplicação de 2.000 a $6.000 \mathrm{~kg} \mathrm{ha}^{-1} \mathrm{de}$ gesso. Não obstante, o incremento nos teores de Ca e S encontrados no tecido foliar de soja (Figuras 4a) com o uso do gesso também foi verificado por Quaggio et al. (1993). Todavia, o acréscimo nos teores de Ca e S verificados por Caires et al. (2002) proporcionou incremento na produtividade da cultura do trigo 20 meses após a aplicação de 3.000 a $9.000 \mathrm{~kg} \mathrm{ha}^{-1}$ de gesso.
$\mathrm{O}$ incremento do teor de $\mathrm{S}$ no tecido foliar apresentou efeito significativo nas doses de gesso, corroborando os resultados obtidos por Nogueira \& Melo (2003) na cultura da soja e de Caires et al. (2002) na cultura do trigo. Houve resposta quadrática para explicar o efeito do gesso no teor de S nas culturas do trigo e da soja. O teor máximo de $\mathrm{S}$ no tecido foliar do trigo foi de $9,68 \mathrm{~g} \mathrm{~kg}^{-1}$ com a adição de $3.300 \mathrm{~kg} \mathrm{ha}^{-1}$ de gesso, considerado alto segundo Malavolta et al. (1997). A partir dessa dose, houve redução no teor de S na cultura do trigo, fato que pode estar relacionado à regulação nas plantas para evitar absorção de luxo de S. Segundo Marschner (1995), na parte aérea das plantas ocorre a assimilação de $\mathrm{S}$ na forma de glutationa, a qual pode atuar como sinalizador para regular a absorção de sulfato pelas raízes.

A soja apresentou comportamento semelhante ao do trigo quanto ao teor de S no tecido foliar em resposta às doses de gesso, visto que no Local 2 (s/Al) o teor máximo de $7,18 \mathrm{~g} \mathrm{~kg}^{-1}$ foi alcançado com a adição de $3.300 \mathrm{~kg} \mathrm{ha}^{-1}$ de gesso, considerado alto segundo Malavolta et al. (1997). O acréscimo no teor de S foliar na cultura da soja também foi verificado por Tanaka \& Mascarenhas (2002), com efeito linear até $6.000 \mathrm{~kg} \mathrm{ha}^{-1}$ de gesso. Todavia, segundo esses autores, com a utilização de $0,2.000,4.000$ e $6.000 \mathrm{~kg} \mathrm{ha}^{-1} \mathrm{de}$ gesso na cultura da soja ocorreram maiores respostas à aplicação de gesso em situações em que a camada subsuperficial apresentou deficiência de Ca e $\mathrm{S}$ e toxidez de $\mathrm{Al}$, assim como observado no Local 1 (c/Al) deste trabalho, com incremento de $\mathrm{S}$ no tecido foliar em resposta à aplicação de $5.000 \mathrm{~kg} \mathrm{ha}^{-1}$ de gesso. $\mathrm{O}$ teor de S no tecido foliar da soja, em ambos os locais, com a adição de gesso estava acima do teor adequado, que é de $4 \mathrm{~g} \mathrm{~kg}^{-1}$ (Malavolta et al., 1997).

\section{Produtividade de trigo e de soja}

A aplicação de doses crescentes de gesso agrícola não influenciou na produtividade das culturas de trigo e de soja, à exceção apenas da cultura do trigo no Local 1 (c/Al), a qual apresentou incremento linear crescente de produtividade, evidenciando a interferência da aplicação de gesso em solos com toxidez por $\mathrm{Al}^{3+}$, descrito por Pavan et al. (1984). É importante destacar que a baixa produtividade na cultura do trigo é decorrente de estiagens que aconteceram no Local 1 (c/Al) e no Local 2 (s/Al) no início do desenvolvimento da cultura, no mês de maio; e no florescimento, no mês de julho, além de problemas com excesso de chuvas na fase de colheita (Figura 1).

Cultivares de soja e trigo tolerantes ao $\mathrm{Al}$ apresentaram crescimento e desenvolvimento normais na presença de elevada saturação por $\mathrm{Al}^{3+}$ no solo, enquanto cultivares de trigo suscetíveis ao $\mathrm{Al}$ tiveram redução no desenvolvimento do sistema radicular, segundo Mascarenhas et al. (1995). Dessa forma, é possível supor que a menor produtividade obtida no Local 1 (c/Al) com a cultura do trigo pode estar relacionada com a presença de $\mathrm{Al}^{3+}$ trocável no solo, 
pois a cultivar CD 104 é moderadamente sensível ao $\mathrm{Al}^{3+}$; contudo, ocorreu aumento na produtividade no Local 1 (c/Al), com a aplicação de gesso. Caires et al. (2002) também constataram aumento da produtividade da cultura do trigo com o uso de gesso em solo com toxidez por $\mathrm{Al}$, como observado no Local 1 (c/Al).

A produtividade da cultura da soja, com a variedade CD 214RR tolerante ao $\mathrm{Al}^{3+}$, não sofreu interferência da utilização das doses de gesso. Tal resultado também foi verificado por Quaggio et al. (1993) na cultivar IAC 11, Caires et al. (1998) nas cultivares BR 16 e FT Abyara, Caires et al. (1999) na cultivar FT 5, Caires et al. (2003) nas cultivares FT 5, FT Abyara e Embrapa 133, Caires et al. (2006) na cultivar CD 206 e Nogueira \& Melo (2003) na cultivar IAC 8, mesmo havendo efeito significativo na melhoria das características químicas do subsolo. No entanto, Raij et al. (1994) observaram efeito significativo na produtividade da soja, cultivar IAC 12 , com o uso de 400 a $10.000 \mathrm{~kg} \mathrm{ha}^{-1}$ de gesso. Entretanto, Sousa et al. (1996) encontraram efeito significativo da produtividade das culturas do trigo e da soja, principalmente em situações de veranicos, devido ao crescimento de raízes profundas promovido pela aplicação de gesso.

$\mathrm{O}$ fato de a cultura da soja neste trabalho não sofrer interferência significativa da adição de gesso em sistema semeadura direta é explicado por Zambrosi et al. (2007), a partir de experimento realizado em sistema plantio direto com a aplicação de gesso. Esses autores observaram que as formas químicas de $\mathrm{Al}$ que mais aparecem na solução do solo são complexos de $\mathrm{Al}$ com ácidos orgânicos dissolvidos e, em menor proporção, $\mathrm{AlSO}_{4}{ }^{+}$. Não obstante, a importância do gesso agrícola em amenizar os efeitos fitotóxicos do $\mathrm{Al}$ parece ser de menor importância em solos sob SPD, devido à intensa complexação desse cátion com compostos hidrossolúveis de baixo peso molecular, como evidenciado por Franchini et al. (2001, 2003), os quais têm origem na decomposição de resíduos vegetais e na exsudação radicular. Assim, $\mathrm{o} \mathrm{Al}^{3+}$ não chega a causar toxidez à cultura da soja, fato também constatado por Silva et al. (1984b), em trabalho no qual compararam o aprofundamento do sistema radicular das culturas de soja e sorgo em solo com alta saturação por $\mathrm{Al}^{3+}$.

Segundo Neis et al. (2010), em Latossolo Vermelho distrófico o sistema plantio direto apresentou maior produtividade de grãos de soja que o cultivo mínimo, independentemente da dose de gesso, mesmo com incremento nos teores de Ca e S. Contudo, a adição de gesso em cultivo mínimo proporcionou incremento da produtividade de soja até a dose de $6.000 \mathrm{~kg} \mathrm{ha}^{-1}$. Dessa forma, a utilização de gesso em sistema semeadura direta pode suprir nutrientes e reduzir a toxidez por Al trocável nas camadas subsuperficiais, como observado neste trabalho, com aumento de Ca e S na cultura da soja, S na cultura do trigo e aumento da produtividade da cultura do trigo, dispensando a interferência de manejos mais agressivos, como o revolvimento do solo para incorporação do gesso.

\section{CONCLUSÕES}

1. Doses de gesso de 1.000 a $5.000 \mathrm{~kg} \mathrm{ha}^{-1}$ resultaram em aumento dos teores de $\mathrm{Ca}^{2+} \mathrm{e} \mathrm{SO}_{4}{ }^{2-}$ nas profundidades do solo de $0-0,10,0,10-0,20$ e $0,20-$ $0,40 \mathrm{~m}$, um ano após a aplicação em solo com e sem $\mathrm{Al}^{3+}$.

2. Houve redução do Al trocável em Latossolo Vermelho eutroférrico de textura argilosa com $\mathrm{Al}^{3+}$ com a aplicação de $3.000 \mathrm{~kg} \mathrm{ha}^{-1}$ de gesso.

3. O uso do gesso em doses de 1.000 a $5.000 \mathrm{~kg} \mathrm{ha}^{-1}$ proporcionou redução linear de $\mathrm{K}^{+}$até $0,10 \mathrm{~m}$ e de $\mathrm{Mg}^{2+}$ até $0,40 \mathrm{~m}$ de profundidade do solo, um ano após a sua aplicação, em ambas as áreas, com ou sem $\mathrm{Al}^{3+}$.

4. A aplicação de gesso aumentou os teores foliares de Ca, Mg, K, S e Al na cultura da soja e reduziu os teores de $\mathrm{Ca}$ e $\mathrm{Mg}$ na cultura do trigo, tanto em solo com $\mathrm{Al}^{3+}$ quanto em solo sem $\mathrm{Al}^{3+}$.

5. O gesso proporcionou incremento do teor foliar de $\mathrm{S}$ nas culturas do trigo e da soja com a dose máxima de $3.300 \mathrm{~kg} \mathrm{ha}^{-1}$ no solo sem $\mathrm{Al}^{3+}$ e em solo com $\mathrm{Al}^{3+}$ com $5.000 \mathrm{~kg} \mathrm{ha}^{-1}$ na cultura da soja e $3.300 \mathrm{~kg} \mathrm{ha}^{-1}$ na cultura do trigo.

6. O uso do gesso aumentou a produtividade do trigo, cultivar CD 104, em solo com $\mathrm{Al}^{3+}$, mas não influenciou na produtividade de soja em ambas os solos, com ou sem $\mathrm{Al}^{3+}$.

\section{AGRADECIMENTOS}

À Coordenadoria de Aperfeiçoamento de Pessoal de Ensino Superior (CAPES), e Fundação Araucária de Apoio ao Desenvolvimento Científico e Tecnológico do Paraná (FUNDAÇÃO ARAUCÁRIA), pela concessão de bolsas de estudo.

\section{LITERATURA CITADA}

ALCARDE, J.A. Corretivos da acidez dos solos: Características e interpretações técnicas. 2ed. São Paulo, ANDA, 1992. 26p. (Boletim Técnico, 6)

ALLEONI, L.R.F.; CAMBRI, M.A. \& CAIRES, E.F. Atributos químicos de um Latossolo de Cerrado sob plantio direto, de acordo com doses e formas de aplicação de calcário. R. Bras. Ci. Solo, 29:923-934, 2005.

ALLEONI, L.R.F.; ZAMBROSI, F.C.B.; MOREIRA, S.G.; PROCHNOW, L.I. \& PAULETTI, V. Liming and electrochemical attributes of an Oxisol under no tillage. Sci. Agric., 60:119-123, 2003. 
BORGES, E.N. Efeito de calcário e gesso nos teores de cálcio e alumínio da camada compactada em Latossolo VermelhoEscuro. Pesq. Agropec. Bras., 32:107-114, 1997.

CAIRES, E.F.; CHURKA, S.; GARBUIO, F.J.; JORIS, H.A.W \& MASCHIETTO, E.R.G. Gesso agrícola na melhoria de atributos químicos do solo e na produção de grãos da sucessão milho-trigo-soja em plantio direto. In: CONGRESSO BRASILEIRO DE CIÊNCIA DO SOLO, 21., Gramado, 2007. Anais. Gramado, 2007. CD-ROM

CAIRES, E.F.; GARBUIO, F.J.; ALLEONI, L.R.F. \& CAMBRI, M.A. Calagem superficial e cobertura de aveia preta antecedendo os cultivos de milho e soja em sistema de plantio direto. R. Bras. Ci. Solo, 30:87-98, 2006.

CAIRES E.F.; BLUM, J.; BARTH, G.; GARBUIO, F.J. \& KUSMAN, M.T. Alterações químicas do solo e resposta da soja ao calcário e gesso aplicados na implantação do sistema plantio direto. R. Bras. Ci. Solo, 27:275-286, 2003.

CAIRES E.F.; FELDHAUS, I.C.; BARTH, G. \& GARBUIO, F.J. Lime na gypsum application on the wheat crop. Sci. Agric., 59:357-364, 2002.

CAIRES, E.F.; FONSECA, A.F.; MENDES, J.; CHUEIRI, W.A. \& MADRUGA, E.F. Produção de milho, trigo e soja em função das alterações das características químicas do solo pela aplicação de calcário e gesso na superfície, em sistema plantio direto. R. Bras. Ci. Solo, 23:315-327, 1999.

CAIRES, E.F.; CHUEIRRI, W.A.; MADRUGA, E.F. \& FIGUEREDO, A. Alterações de características químicas do solo e resposta ao calcário e gesso aplicados na superfície em sistema de cultivo sem preparo do solo. R. Bras. Ci. Solo, 22:27-34, 1998.

DELHAIZE, E.; CRAIG, S. BEATON, C.D.; BENNET, E.J. JAGADISH, V.C. \& RANDALL, P. Aluminium tolerance in Wheat (Triticum aestivum L.) Plant Physiol., 103:685693, 1993.

DIAS, L.E. Uso de gesso como insumo agrícola. Seropédica, Embrapa - Centro Nacional de Pesquisa de Biologia . CNPBS, 1992. 6p. (Comunicado Técnico 7)

EMPRESA BRASILEIRA DE PESQUISA AGROPECUÁRIA EMBRAPA. Centro Nacional de Pesquisa de Solos. Sistema brasileiro de classificação de solos. Brasília, Embrapa Produção de Informação, 2006. 306p.

EMPRESA BRASILEIRA DE PESQUISA AGROPECUÁRIA . EMBRAPA. Manual de análises químicas de solos, plantas e fertilizantes. Brasília, Embrapa Solos/Embrapa Informática Agropecuária/Embrapa Comunicação para Transferência de Tecnologia, 1999. 370p.

EMPRESA BRASILEIRA DE PESQUISA AGROPECUÁRIA EMBRAPA. Centro de Pesquisa de Solos. Manual de métodos de análise do solo. Rio de Janeiro, 1997. 212p.

FRANCHINI, J.C.; HOFFMANN-CAMPO, C.B.; TORRES, E.; MIYAZAWA, M. \& PAVAN, M.A. Organic composition of green manures during growth and its effect on cation mobilization in an acid Oxisol. Comm. Soil Sci. Plant Anal., 34:2045-2058, 2003.
FRANCHINI, J.C.; GONZALEZ-VILLA, F.J.; MIYAZAWA, M. \& PAVAN, M.A. Rapid transformations of plant water soluble organic compounds in relation to cation mobilization in acid Oxisol. Plant Soil, 231:55-63, 2001.

HAYNES, R.J. Active ion uptake and maintenance of cationanion balance: A critical examination of their role in regulating rhizosphere $\mathrm{pH}$. Plant Soil, 126:247-264, 1990.

MALAVOLTA, E.; VITTI, G.C. \& OLIVEIRA, S.A. Avaliação do estado nutricional das plantas, princípios e aplicações. Piracicaba, Associação Brasileira para a Pesquisa da Potassa e do Fosfato, 1997. 319p.

MARKET, C.M.; PAVANA, M.A. \& LANTMANN, A.F. Considerações sobre o uso do gesso na agricultura. Piracicaba, POTAFOS - Associação Brasileira para Pesquisa da Potassa e do Fosfato, 1987. 3p. (Informações Agronômicas 40)

MARSCHNER, H. Mineral Nutricion of Higher Plants. 2.ed., San Diego, Academic Press. 1995. 889p.

MASCARENHAS, H.A.A. \& TANAKA, R.T. Crescimento em vasos, de cultivares de soja e de trigo em função da saturação de alumínio. Sci. Agric., 52:257-262, 1995.

NEIS, L.; PAULINO, H.B.; SOUZA, E.D.; REIS, E.F. \& PINTO, F.A. Gesso agrícola e rendimento de grãos de soja na região do sudoeste de Goiás. R. Bras. Ci. Solo, 34:409416, 2010.

NOGUEIRA, M.A. \& MELO, W.J. Enxofre disponível para a soja e atividade de arilsulfatase em solo tratado com gesso agrícola. R. Bras. Ci. Solo, 27:655-663, 2003.

PAVAN, M.A. Comportamento do gesso nos solos ácidos das regiões tropicais e subtropicais. Piracicaba, POTAFOS Associação Brasileira para Pesquisa da Potassa e do Fosfato, 1986. 3p. (Informações Agronômicas 35)

PAVAN, M.A.; BINGHAM, F.T. \& PRATT, P.F. Redistribution of exchangeable calcium, magnesium, and aluminum following lime or gypsum applications to a Brasilian Oxisol. Soil Sci. Soc. Am. J., 48:33-38, 1984.

PIMENTEL-GOMES, F. Curso de estatística experimental. 12.ed. São Paulo, Nobel,1987. 466p.

QUAGGIO, J.A.; RAIJ, B. van; GALLO, P.B. \& MASCARENHAS, H.A.A. Respostas da soja à aplicação de calcário e gesso e lixiviação de íons no perfil do solo. Pesq. Agropec. Bras., 28:375-383, 1993.

RAIJ, B. van; MASCARENHAS, H.A.A.; PEREIRA, J.C.V.N.A.; IGUE, T. \& SORDI, G. Efeito de calcário e de gesso para soja cultivada em Latossolo Roxo ácido saturado com sulfato. R. Bras. Ci. Solo, 18:305-312, 1994.

RAMOS, L.A.; NOLLA, A.; KORNDORFER, G.H. \& CAMARGO, M.S. Reatividade de corretivos da acidez e condicionadores de solo em colunas de lixiviação. R. Bras. Ci. Solo, 30:849-857, 2006.

ROSOLEM, C.A. \& MACHADO, J.R. Efeitos da calagem e gessagem na produção de algodão e na lixiviação de bases em dois Latossolos. R. Bras. Ci. Solo, 8:103-109, 1984. 
ROTH, C.H.; PAVAN, M.A.; CHAVES, J.C.D.; MEYER, B. \& FREDE, H.G. Efeito das aplicações de calcário e gesso sobre a estabilidade de agregados e infiltrabilidade de água em um Latossolo Roxo cultivado com cafeeiros. R. Bras. Ci. Solo, 10:163-166, 1986.

SAEG. Sistema para análises estatísticas. Versão 8.0. Viçosa, MG, Universidade Federal de Viçosa, 1999.

SHAINBERG, I.; SUMNER, M.E.; MILLER, W.P.; FARINA, M.P.W.; PAVAN, M.A. \& FEY, M.V. Use of gypsum on soils: A Review. Adv. Soil Sci., 9:1-111, 1989.

SILVA, C.E.M.; GONÇALVES, J.F.C.; FELDPAUSCH, T.R.; LUIZÃO, F.J.; MORAIS, R.R. \& RIBEIRO, G.O. Eficiência no uso dos nutrientes por espécies pioneiras crescidas em pastagens degradadas na Amazônia Central. Acta Amaz., 36:503-512. 2006.

SILVA, N.M.; RAIJ, B. van, \& CARVALHO, L.H. Efeitos do calcário e do gesso nas características químicas do solo e na cultura do algodão. Bragantia. [online]. 56:389-401, 1997. Disponível em: <http://www.scielo.br> Acesso em 12 jun. 2010.

SILVA, J.B.C.; NOVAIS, R.F. \& SEDIYAMA, C.S. Comportamento de genótipos de soja em solo com alta saturação de alumínio. Pesq. Agropec. Bras., 19:287-298, 1984a.

SILVA, J.B.C.; NOVAIS, R.F. \& SEDIYAMA, C.S. Identificação de genótipos de sorgo tolerantes à toxicidade de alumínio. R. Bras. Ci. Solo, 8:77-83, 1984b.

SORATTO, R.P.; CRUSCIOL, C.A.C. \& MELLO, F.F.C. Componentes da produção e produtividade de cultivares de arroz e feijão em função de calcário e gesso aplicados na superfície do solo. Bragantia, 69:965-974, 2010.
SORATTO, R.P. \& CRUSCIOL, C.A.C. Atributos químicos do solo decorrentes da aplicação em superfície de calcário e gesso em sistema plantio direto recém-implantado. R. Bras. Ci. Solo, 32:675-688, 2008a.

SORATTO, R.P. \& CRUSCIOL, C.A.C. Produção de fitomassa e acúmulo de nutrientes pela aveia-preta em função da aplicação de calcário e gesso em superfície na implantação do sistema plantio direto. Ci. Rural, 38:928-935, 2008b.

SORATTO, R.P. \& CRUSCIOL, C.A.C. Cátions hidrossolúveis na parte aérea de culturas anuais mediante aplicação de calcário e gesso em superfície. R. Bras. Ci. Solo, 31:81-90, 2007.

SOUSA, D.M.G.; LOBATO, E. \& REIN, T.A. Uso do gesso agrícola nos solos dos Cerrados. Planaltina, EMBRAPACPAC, 1996. 20p. (Circular Técnica 32)

TANAKA, R.T. \& MASCARENHAS, H.A.A. Resposta da soja à aplicação de gesso agrícola. Campinas, Instituto Agronômico 54, 2002. 2p.

ZAMBROSI, F C.B ; ALLEONI, L.R.F \& CAIRES, E.F. Aplicação de gesso agrícola e especiação iônica da solução de um Latossolo sob sistema plantio direto. Ci. Rural, 37:110-117, 2007.

WADT, P.G.S. Alterações eletroquímicas de um Latossolo Vermelho-Amarelo tratado com carbonato e sulfato de cálcio. Sci. Agric. [online], 57:519-524, 2000. Disponível em: <http://www.scielo.br> Acesso em 12 jun. 2010

WADT, P.G.S. \& WADT, L.H.O. Movimentação de cátions em amostras de um Latossolo Vermelho-Amarelo incubadas com duas fontes de cálcio. Sci. Agric. [online], 56:11571164. 1999. Disponível em: <http://www.scielo.br> Acesso em 12 jun. 2010. 